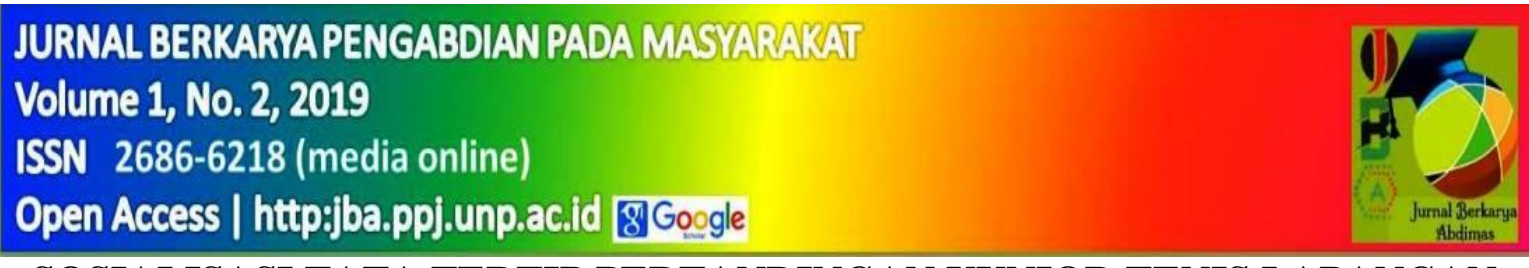

SOSIALISASI TATA TERTIP PERTANDINGAN YUNIOR TENIS LAPANGAN PADA ORANG TUA DAN PELATIH ATLET TENIS YUNIOR SE SUMATERA

\author{
Rices Jatra ${ }^{1}$, Rezki, Daharis ${ }^{2}$, Sesi Melati $^{3}$ \\ Riau Islamic University \\ ricesjatra@edu.uir.ac.id ${ }^{1}$,rezki@edu.uir.ac.id ${ }^{2}$, daharispenjas@edu.uir.ac.id ${ }^{3}$, \\ penjas@edu.uir.ac.id
}

\begin{abstract}
ABSTRACK
Kegiatan ini bertujuan untuk memberikan Pengetahuan mengenai Tata Tertip Pertandingan Tenis Yunior Nasional pada orang tua dan Pelatih Atlet Tenis Yunior Se Sumatera, supaya orang tua dan pelatih Mampu memahami tentang tata tertip Pertandingan Tenis Yunior sehingga mampu memberikan pengetahuan dan melatih anak didiknya supaya bias bertanding sesui denga tata Tertip yang diatur oleh PP PELTI untuk Kejuaraan Yunior Nasional TDP( Turnamen Diakui PELTI). Hal ini mengacu pada peraturan ITF ( International Tennis Federation) sehingga nnati para pelatih dan Orang tua mudah dalam mendidik dan Melatih anaknya untuk bermain sesuai dengan Tata Tertip yang telah di Atur. Kegiatan meliputi "Sosialisasi Tata Tertip Pertandingan Yunior Tenis Lapangan pada Orang Tua dan Pelatih Atlet Tenis Yunior Se Sumatera". Kegiatan ini dilaksanakan pada tanggal 4 sd 6 April 2019 di kecamatan Kubung kabupaten Solok Sumatera Barat. kegiatan diikuti oleh 30 orang Pelatih dan Orang Tua atlet yang Bertanding di Kejuaraan Nasional tenis di Piala Bupati Solok II tahun 2019.

kata Kunci: Tata Tertip, Pertandingan tenis
\end{abstract}

\title{
SOCIALIZATION OF THE CODE OF CONDUCTTENNIS JUNIOR TOURNAMENT FOR THE PARENTS AND THE COACH OF THE JUNIOR TENNIS ATHLETES IN SUMATERA".
}

\author{
Rices Jatra, Rezki, Daharis, Sesi Melati \\ Riau Islamic University \\ ricesjatra@edu.uir.ac.id,rezki@edu.uir.ac.id, daharispenjas@edu.uir.ac.id,
}

Abstrack

This activity aims to provide Knowledge on the Rules of National Junior Tennis Matching for Parents and Trainers of Junior Tennis Athletes in Sumatra, so that parents and coaches are able to understand the rules of the Junior Tennis Match so that they can provide knowledge and train their students to compete Written procedures arranged by PP PELTI for the TDP National Junior Championship (PELTI Recognized Tournament). This refers to the ITF (International Tennis Federation) regulations so that coaches and parents are easy to educate and train their children to play in accordance with the Ordered Rules that 
have been arranged. The activity included Socialization Of The Code Of Conduct Tennis Junior Tournament For The Parents And The Coach Of The Junior Tennis Athletes In Sumatera".This activity was held on April 6, 2019 in Kecamatan Kubung, Kabupaten Solok, West Sumatra. The activity was attended by 30 coaches and parents of athletes who competed in the national tennis championship at the Solok II Regent Cup in 2019.

Key words: Code Of Conduct, Tennis Match

\section{ANALISIS SITUASI}

Tenis Lapanganadalah salah satu cabang olahraga yangdigemari oleh banyak kalangan masyarakat Indonesia. Hal ini terlihat banyaknya orang yang bermain tenis mulai dari anak anak sampai veteran. Dilihat dari pertandingan, turnament tenis lapangan mulai dari tingkat kelompok umur sampai kelompok veteran. Peraturan Turnamen diakui PELTI kelompok umum tahun 2018 menyebutkan 'Pertumbuhan dan perkembangan tenis nasional dewasa ini telah menunjukan tingkat kemajuan cukup berarti, perlu terus dijaga dan ditumbuhkembangkan lebih lanjut sehingga mampu berbicara secara lebih mantap dipercaturan tenis international (PP PELTI, 2018).

Untuk itu perlu dukungan sepenuhnya dari setiap perangkat organisasi agar prestasi menyeluruh dari para pemain, official, dan penyelenggara setiap turnament mampu mencapai sasaran yang telah ditetapkan. Penyelenggara turnamen harus mampu menjadikan turnament itu sukses dan tepat sasaran. Untuk mencapai itu penyelenggara turnamen perlu dibentuk kepanitian yang bertugas dibidang teknis pertandingan dan unsur unsur pendukung lainnya yang besifat non teknis.

Sedangkan hal tersebut di atas sesuai dengan pendapat (Arie Asnaldi; \& Padang), 2016) menyatakan "Seiring berjalannya waktu perkembangan ilmu pengetahuan serta teknologi dewasa ini yang berlangsung dengan cepat, banyak menyebabkan pergeseran nilai-nilai kehidupan, baik itu nilai sosial, budaya,ekonomi, politik bahkan tanpa terkecuali nilai-nilai olahraga itu sendiri”. Dalam aturan turnamen umum PELTI panitia atau petugas teknis pertandngan terdiri dari 1) direktur turnamen, 2) pengawas Pertandingan 3) Wasit kepala 4) wasit 5)hakim garis 6) pemungut bola, 7) Penunjuk angka, 8)petugas Meja, 9),Urusan Kesehatan Pemain, 10) Urusan Perlengkapan, 11) Promosi, tiket, keamanan dan urusan umum(PP PELTI, 2018).

Dari segi atlet sendiri orang tua dan pelatih sangat berperan dalam perkembangan atlet baik itu untuk mencapai prestasi mapun untuk kebugaran.(Rahmawati, 2017) menjelaskan Profil atlet: Secara antropometrik dan fisik, atlet yang telah menjadi binaan PELTI sebagian besar tidak memiliki kesesuaian potensi bakat. Orang tua juga sangat berpengaruh kepada prestasi seorang atlet, tampa dukungan penuh orang tua susah juga seorang atlet mencapai prestasi tinggi sebagaimana yang dikatakan oleh (Maksum, 2006).

Prestasi yang dicapai seorang anak berkaitan langsung dengan sampai sejauh mana harapan orang tua terhadap prestasi yang ingin dicapai anaknya. Seorang anak yang orang tuanya berharap ia menjadi atlet besar, akan memiliki kesempatan yang lebih tinggi dibanding seorang anak yang orang tuanya tidak memiliki harapan. Jadi orang tua harus mendukung anaknya sehingga anak memiliki kepercayaan diri yang besar dalam latihan meraih prestasi.

Selain orang tua yang berperan pada atlet yaitu seorang pelatih. Pelatih berperan penting dalam mentransfer ilmu kepada atlet. Disamping itu pelatih juga mengajarkan 
bahgaimana atlet memiliki kepribadian yang bagus. Maksum menambahkan seiring dengan proses pelatihan yang dilakukan, pelatih seringkali mengajarkan sikap, kebiasaan, nilai dan tingkahlaku kepada atletnya.

Dengan kata lain, seorang pelatih masih juga melakukan proses pengasuhan. Pengasuhan yang berintikan pada pengajaran sistem nilai tersebut biasanya dikaitkan langsung dengan upaya meraih prestasi tinggi, seperti masalah kedisiplinan dan komitmen terhadap profesi(Maksum, 2006). Pada pertandingan tenis lapangan banyak kita lihat di Indonesia ini atlet atlet Junior didampingi oleh orang tua dan pelatih saat pertandingan.

Hal ini terbukti disetiap setiap turnamen junior banyak orang tua berada mendampingi atlet dengan tujuan supaya anaknya bisa menjalankan pertandingan dengan baik dalam meraih apa yang di inginkan. Seiring Pertumbuhan dan perkembangan tenis yunior nasional dewasa ini yang telah menunjukkan tingkat kemajuan cukup berarti, perlu terus dijaga dan ditumbuh kembangkan lebih lanjut sehingga mampu berbicara secara lebih mantap dipercaturan tenis yunior internasional. Untuk itu perlu dukungan sepenuhnya dari setiap perangkat organisasi agar prestasi menyeluruh dari para pemain, offisial dan penyelenggara setiap turnamen mampu mencapai sasaran yang telah ditetapkan. Beserta dukungan orang tua dan pelatih dalam mencapai prestasi anak didik atau anak latihnya.

\section{SOLUSI DAN TARGET}

Untuk itu setiap turnamen perlu penataan dan pengaturan kegiatan diarahkan dan ditunjang oleh seperangkat ketentuan yang selanjutnya diatur sebagaimana ditetapkan dalam peraturan turnamen diakui PELTI ( TDP ) yunior yang berkaitan dengan Tata tertip Pertandingan Yunior. Tata tertip adalah aturan aturan yang harus ditaaati oleh seorang atlet dalam mengikuti pertandingan tenis lapangan. Saat ini banyak para pemain pelatih maupun orang tua, tidak mengetahui banyak mengenai tata tertip, sehingga untuk mencapai ke profesionalan dalam turnamen usah terwujud dengan baik, maka dari itu perlu rasanya menosialiasikan tata tertip Pertandingan Tenis Yunior kepada Orang tua dan pelatih atlet Tenis Yunior Sesumatera. Diantaranya Tata Tertip Turnamen Yunior Tenis Lapangan dalam aturan yang dibuat oleh PP PELTI tahun 2019(PP PELTI, 2019) Sebagai berikut:

\section{A. Sistem Pertandingan}

\section{Babak Kualifikasi}

Babak Kualifikasi dimainkan dengan menggunakan sistem gugur The Best of Two Super Tie-break Sets. Bila jumlah peserta, kapasitas lapangan dan waktu yang tersedia tidak mencukupi, maka dapat menggunakan sistem Pro-Set, atau Short-Set, atau Deciding Match Tie-break (10 points). Khusus untuk Babak Kualifikasi Ganda menggunakan sistim ProSet. Dalam hal ini melihat situasi dan kondisi saat pertandingan, karna lapangan pertandingan menggunakan lapangan outdor kemungkinan hari hujan dan peserta yang banyak.

\section{Babak Utama}

Babak Utama dimainkan dengan menggunakan sistem gugur The Best of Three Tie break Sets. 


\section{B. Jadwal Pertandingan}

1. Pertandingan harus berlangsung setiap hari secara berturut-turut dan berakhir pada hari Sabtu atau Minggu.

2. Jadwal Pertandingan Harian ( Order of Play )

a. Disusun oleh Referee dengan berkonsultasi dengan Direktur Turnamen

b. Harus diketahui peserta paling lambat jam 20.00 waktu setempat, semalam sebelum pertandingan.

c. Ditempatkan di lapangan pertandingan dan official hotel, dan dipasang/ ditempatkan di tempat yang mudah dibaca oleh seluruh peserta.

3. Apabila TDP Yunior mempertandingkan Putra dan Putri, diusahakan agar pertandingan putri dijadwalkan lebih awal dari pertandingan putra.

4. Urutan pertandingan bebas, dan dapat disesuaikan dengan kepentingan promosi dan atau demi kelancaran pertandingan.

5. Setiap Peserta Babak Utama tidak boleh bertanding lebih dari satu kali di nomor yang sama kecuali dalam keadaan terpaksa (force majeur).

6. Pertandingan Ganda, setiap harinya diupayakan dimainkan setelah selesai pertandingan Tunggal.

\section{B o l a}

\section{Penggunaan Bola}

a. Bola yang digunakan delam setiap pertandingan (match) paling sedikit 3 (tiga) buah bola dan harus baru.

b. Bola untuk latihan pemain (practice ball), cukup dengan bola bekas.

\section{Penggantian Bola}

a. Untuk sistem The Best of Three Tie-break Sets, penggantian bola dila-kukan hanya bila terjadi 1 set all (rubber set), dan atau pada set terakhir.

b. Untuk sistem yang lainnya seperti, Pro-Sets, Short-Sets, Deciding Match Tie break, tidak direkomendasikan untuk menganti bola.

\section{Istirahat Pemain}

\section{Tenggang waktu antara Turnamen.}

Bila Referee/Pengawas Pertandingan diberitahu oleh Pemain bahwa ia baru menyelesaikan pertandingan final suatu TDP perorangan/beregu pada minggu sebelumnya, Referee/Pengawas Pertandingan dapat memberi waktu istirahat selama satu hari untuk pertandingan pertamanya (bila ia harus main pada Babak Kualifikasi). Bila hal ini tidak memungkinkan maka Pemain tersebut akan dijadwalkan bertanding pada giliran bertanding terakhir untuk pertandingan pertamanya.

\section{Antara Babak Kualifikasi dan Babak Utama}

Pemain yang lolos Babak Kualifikasi diberi tenggang waktu sedikitnya 12 jam untuk bertanding di Babak Utama.

\section{Tenggang waktu antara Pertandingan Tunggal dan Ganda.}

Apabila seorang Pemain harus menyelesaikan pertandingan nomor tunggal dan nomor ganda pada hari yang sama, maka ia diberi waktu istirahat dari pertandingan nomor tunggal ke pertandingan nomor ganda sbb : 
a. Bila bermain kurang dari 1 jam, istirahat 30 menit

b. Bila bermain kurang dari 1 jam s/d 11/2 jam, istirahat 1 jam

c. Bila bermain lebih dari $11 / 2$ jam, istirahat $11 / 2$ jam.

\section{E. Cedera ( Injury )}

1. Cedera adalah cedera yang terjadi selama bertanding dilapangan, termasuk kejang otot. Bila Pemain mengalami cedera saat bertanding sehingga mengganggu permainannya,maka Pemain tersebut dapat meminta untuk perawatan cederanya (Medical time-out) selama 3 menit. Permintaan harus diajukan segera kepada Wasit agar mendapatkan perawatan dari Dokter Pertandingan. Waktu perawatan 3 menit dihitung sejak dokter atau tim medis mulai memberikan perawatan.

2. Pemain diijinkan meminta perawatan kembali bila mengalami cedera baru pada bagain tubuh yang berbeda : dengan prosedur yang sama.

3. Setelah mendapat waktu perawatan cedera selama 3 menit Pemain tersebut masih diperbolehkan mendapat perawatan lanjutan untuk cedera yang sama sebanyak 2 kali saat pindah tempat selama 90 detik atau istirahat antara set (set break) selama 120 detik.

4. Apabila Dokter/Perawat tidak segera berada dilapangan, maka waktu perawatan cedera dapat ditunda dan pertandingan dilanjutkan sampai Dokter/Perawat datang dilapangan dan siap untuk merawat.

5. Pemain hanya boleh menerima perawatan sebanyak 1 kali untuk cedera yang sama dan untuk semua kram dalam suatu pertandingan.

6. Kondisi yang tidak dapat menerima Perawatan :

Pemain tidak dapat menerima perawatan selama pertandingan termasuk pemanasan, sesuai dengan kondisi kondisi sbb:

a. Setiap penyakit atau kondisi kesehatan, yang ditetapkan oleh dokter dan atau petugas medis bahwa tidak akan bertambah baik bila diberikan perawatan.

b. Diderita sejak sebelum pertandingan atau bukan terjadi pada saat per-tandingan

c. Pemain yang mengalami Kelelahan umum (General player fatique).

d. Semua kondisi yang membutuhkan suntikan, infus atau oksigen, kecuali untuk penderita penyakit gula (diabetes).

\section{F. Prosedure medical time Out.}

\section{Selama pemanasan.}

Jika pemain mengalami cedera pada saat pemanasan, pemain dapat menerima perawatan cedera 3 menit (medical time out) atau perawatan dengan waktu 90 detik (medical treatment) setelah selesai waktu pemanasan. Perawatan cedera 3 menit yang dilakukan pada saat pemanasan maka dinyatakan bahwa pemain tersebut telah menggunakan kesempatan perawatan cederanya. Apabila setelah menerima perawatan, pemain tidak dapat melakukan pertandingan maka pertandingan tersebut tidak boleh dilaksanakan (pemain tersebut dinyaatakan kalah).

\section{Selama Pertandingan.}

Pemain dapat meminta dan menerima perawatan cedera segera setelah cedera terjadi atau ditunda pada saat istirahat pindah tempat atau istirahat antar set, atau pada saat dokter tiba dilapangan. Jika pertandingan dihentikan sampai dokter tiba dilapangan dan perawatan 
telah selesai dilakukan, pertandigan harus segera dimulai. Bila penghentian tersebut lebih dari 15 menit, maka akan dilakukan pemanasan ulang.

\section{Sebagai tambahan :}

Wasit dapat menghentikan pertandingan dan memanggil dokter kelapangan untuk memberikan nasehat kepada pemain bahwa, kelanjutan pertandingan tersebut akan lebih memperparah kondisi kesehatan pemain. Dalam kasus ini Referee dapat memutuskan untuk menghentikan pertandingan (pemain tersebut dinyatakan kalah dengan retired).

\section{G. Ijin ke Kamar Kecil (Toilet Break)}

Atas seijin wasit pemain dibolehkan meninggalkan lapangan untuk kekamar kecil dalam waktu yang wajar.

1. Ijin kekamar kecil harus diambil pada saat istirahat antar set (set break).

2. Untuk pertandingan dengan sistem The best of Three, pemain diberikan ijin sebanyak satu kali. Dalam pertandingan ganda setiap pasangan iberikan ijin sebanyak 2 kali. Jika salah satu pasangan meninggalkan lapangan secara bersama-sama, maka dihitung $1 \mathrm{kali}$ ijin kekamar kecil.

3. Setiap pemain/pasangan yang meninggalkan lapangan untuk kekamar kecil, dihitung sebagai ijin kekamar kecil tanpa memperhatikan apakah lawannya telah atau belum mengambil ijin kekamar kecil.

4. Setiap ijin kekamar kecil yang diambil setelah/sedang pemanasan dimulai maka dihitung telah mengambil kesempatan yang dimiliki untuk ijin ke kamar kecil.

5. Penambahan ijin kekamar kecil diperkenankan namun akan dihukum dengan pelanggaran waktu (Point Penalty Schedule) bila pemain tidak siap dalam waktu yang telah ditetapkan. (120 detik istirahat antar set).

6. Untuk pemain putri, ijin kekamar kecil diberikan sebanyak 2 kali dalam satu pertandingan tunggal dan maksimum 2 kali ijin kekamar kecil untuk satu timdalam satu pertandingan ganda.

Catatan untuk Toilet break : Ijin kekamar kecil hanya boleh digunakan untuk buang air besar/buang air kecil atau ganti pakaian. Selama Ijin kekamar kecil Pemain tidak diperkenankan untuk mene-rima petunjuk dari siapapun. Kekamar kecil hanya dapat dilakukan pada saat set Breaks atau pada saat diawal set dan diakhir set. Pelanggaran ketentuan ini akan dikenakan hukuman pelanggaran kode etik.

\section{METODE PELAKSANAAN}

Program kegiatan yang akan di laksanakan berupa Pemahaman Mengenai tata tertip Pertandingan Tenis Yunior kepada Orang tua dan pelatih atlet Tenis Yunior Sesumatera.Peserta adalah merupakan orang tua dan pelatih atlet yunior Kejuaraan Nasional yang berasal dari berbagai daerahdi sumatera berjumlah sekitar 27 orang, di Lapangan Tenis Koto Baru Kab Solok. Dengan metode pelaksanaan sebagai berikut:

\begin{tabular}{|c|c|c|c|c|}
\hline $\begin{array}{c}\text { Hari/ } \\
\text { Tanggal }\end{array}$ & waktu & Jenis kegiatan & tempat & $\begin{array}{c}\text { Penanggung } \\
\text { jawab }\end{array}$ \\
\hline $\begin{array}{c}\text { Jumat/ } \\
\text { 5April 2019 }\end{array}$ & 08-00-08.30 & Pembukaan & $\begin{array}{c}\text { Lapangan } \\
\text { dan } \\
\text { Tribune }\end{array}$ & Panitia \\
\hline
\end{tabular}




\begin{tabular}{|l|l|c|c|l|}
\hline & $\begin{array}{l}08-30 \mathrm{sd} \\
10.00\end{array}$ & $\begin{array}{c}\text { Tata Tertip Mengenai } \\
\text { Sistem Pertandingan, } \\
\text { jadwal dan Bola }\end{array}$ & $\begin{array}{c}\text { Tribune } \\
\text { Lapangan }\end{array}$ & Rezki,M.Pd \\
\hline 12.00 & $\begin{array}{c}\text { Tata Tertip Mengenai } \\
\text { Istirahat pemain dan } \\
\text { Cidera }\end{array}$ & $\begin{array}{c}\text { Tribune } \\
\text { Lapangan }\end{array}$ & $\begin{array}{l}\text { Rices Jatra,M.Pd, } \\
\text { Rezki, M.pd }\end{array}$ \\
\hline $12.00 \mathrm{sd}$ & $\begin{array}{c}\text { Tata Tertip Mengenai } \\
\text { Prosedur Medical Time } \\
\text { Out dan Ijin ke kamar } \\
\text { kecil }\end{array}$ & Lapangan & $\begin{array}{c}\text { Rices Jatra,M.Pd, } \\
\text { Rezki, M.Pd }\end{array}$ \\
\hline
\end{tabular}

\section{HASIL DAN PEMBAHASAN}

Sosialisasi awalnya diskusi dengan beberapa orang tua dan pelatih yang ada di provinsi Riau bahwasanya banyak masukan mengenai bagaimana pertandingan tenis yunior nasional itu. Baik dari segi penyelenggara dalam menyalenggarakan pertandingan, ataupun sebagai orang tua ataupun pelatih serta bagaimana prosedur mengenai aturan aturan dalam permainan tenis. Sehingga sebagai orang tua maupun pelatih tahu dan bisa menerapkan pada atlet dalam mengikuti pertandingan maupun menyelenggarakan pertandingan dan tahu apa saja yang dibutuhkan untuk membuat sebuah kejuaraan tenis yunior nasional tenis lapangan.

Hal ini terbuka luas dengan adanya kejuaraan tenis yunior nasional yang berada di provinsi Sumatera Barat dengan adanya ini maka orang tua maupun pelatih akan mengantarkan anaknya untuk ikut dalam pertandingan tenis yunior nasional tersebut. Sehingga nanti memudahkan dalam memberikan sosialisasi mengenai tata tertip pertandingan Nasional tenis lapangan yunior. Alhamdulillah kegiatan dapat terlaksana dengan baik dengan peserta berasal dari berbagai macam provinsi dan daerah di Sumatera.

Berdasarkan hasil pengamatan selama kegiatan pengabdian berlangsung diperoleh hasil yang positif diantaranya sebagai berikut: 1) Para peserta orang tua dan pelatih mendapatkan pengetahuan baru mengenai tata tertip sistem pertandingan nasional, babak kualifikasi babak utama, jadwal pertandingan, bola, istirahat pemain, cidera, prosedur MTO, Toilet break. 2) Para peserta aktif bertanya, mulai dari sosialisasi sampaiakhir sehingga menghidupkan suasana dalam kegiatan apalagi ada beberapa orang tua berniat akan mengadakan event kejuaraan tenis yunior nasional, 3) Para peserta sangat antusias karna tata tertip ini sangat dibutuhkan oleh orang tua dan pelatih supaya nanti saat pertandingan anaknya bermain tidak terjadi kesalah pahaman antara orang tua dan wasit, panitia kesehatan dan penyelenggara turnament.

Salah satu contoh dalam kasus toilet break, seorang atlet tidak bisa seenaknya saja keluar lapangan ketoilet, karna ada aturan yang harus dipatuhi sehingga dengan tahu tentang tata tertip atlet bisa menyesuaikan kapan dia kekamar kecil misalnya sebelum pertandingan dia ke toilet terlebih dahulu. Adalagi beberapa kasus diantara masalah kram, dalam (ITF World Tennis tour Juniors, 2019) "Muscle Cramping: A player may receive treatment for muscle cramping only during the time allotted for change of ends and/or set breaks. Players may not receive a Medical Time-Out for muscle cramping. Hal diatas menjelaskan bahwa Otot kram: seorang pemain dapat menerima perawatan untuk kram otot 
hanya selama waktu istirahan dalam pertandingan atau waktu istirahat. Pemain tidak menerima Medical Time-Out untuk kram otot.

Jadi tidak ada perawatan khusus untuk pemain yang mengalami kram, jadi apabila pemain mengalami kram maka dia hanya bisa mendapatkan perawatan saat istirahat game ganjil atau juga saat istirahat antara set yang waktunya 90 detik antara games dan 120 detik di istirahat set. Berbeda dengan pemain sakit, cidera dimana apabila pemain sakit atau cidera maka atlet bisa dapat perawatan 3 menit untuk yang tidak kelihatan yang diatur dalam (International Tennis federation ITF, 2019)a player suffering from a treatable medical condition may be allowed one medical time-out of three minutes for the treatment of that medical condition dan 5 menit apabila cideranya itu kelihatan seperti keluar darah sesuai dalam (International Tennis Federation ITF, 2019) "the ITF Supervisor/Referee or Chair Umpire may allow up to a total of five (5) minutes to assure control of the bleeding".

Wasit akan memberikan waktu 5 menit kalau terjadi pendarahan. Dalam kasus ini terkadang orang tua tidak mengetahui sehingga disaat kram orang tua terkadang meminta segera medis atau dokter. Padahal hal itu akan merugikan atletnya. Kasus ini masih banyak yang terjadi pada mereka selama mengikuti pertandingan baik di tingkat daerah maupunnasional. Sosialisasi ini memberikan masukan positif pada orang tua dan pelatih sehinga kedepananaknya sudah tahu mengenai tata tertip.

Orang tua dan pelatih tidak salah paham lagi mengenai tata tertip pertandingan tenis lapangan. Karna tata tertip itu harus dipatuhi sebagaimana yang dikatakan oleh (Rahmawati, 2017)'Kewajiban Atlet 1. Mengikuti jadwal latihan yang dijadwalkan oleh PELTI. 2. Melaksanakan kegiatan pertandingan sesuai yang telah dijadwalkan PELTI. 3. Mentaati tata tertip yang dibuat PELTI'. Salah satu poin dari kutipan diatas menjelaskan bahwa atlet berkewajiban mentaati tata tertip yang dibuat oleh PP PELTI. Dengan adanya tata tertip nanti atlet akan lebih disiplin, disiplin ini merupakan karakter yang harus ada pada atlet apapun olahraganya sebagaimana yang dikatakan (harris, 2007)

Disiplin adalah bentuk perilaku mematuhi peraturan dan tata tertib dalam aktivitas pendidikan jasmani dan olahraga. Dengan mematuhi tata tertip maka akan menjadikan kita disiplin dalam aktivitas baik itu aktivitas sehari hari maupun aktivitas olahraga jasmani yang dalam hal ini adalah tata tertip pertandingan yang harus dipatuhi oleh atlet. Sehingga atlet akan terbiasa dengan budaya disiplin setiap saat dan hal ini akan memberikan nilai baik pada pertumbuhan anak dimasa dewasa sebagaimana yang dikatakan oleh (Firdaus, 2012) "demikian pula orang yang terbiasa disiplin, maka bisa jadi ia tidak hanya disiplin ketika bekerja, melainkan juga ketika melakukan kegiatan di rumah atau di masyarakat.

Artinya ada generalisasi tingkah laku terhadap beberapoa situasi yang merupakan stimulus". 


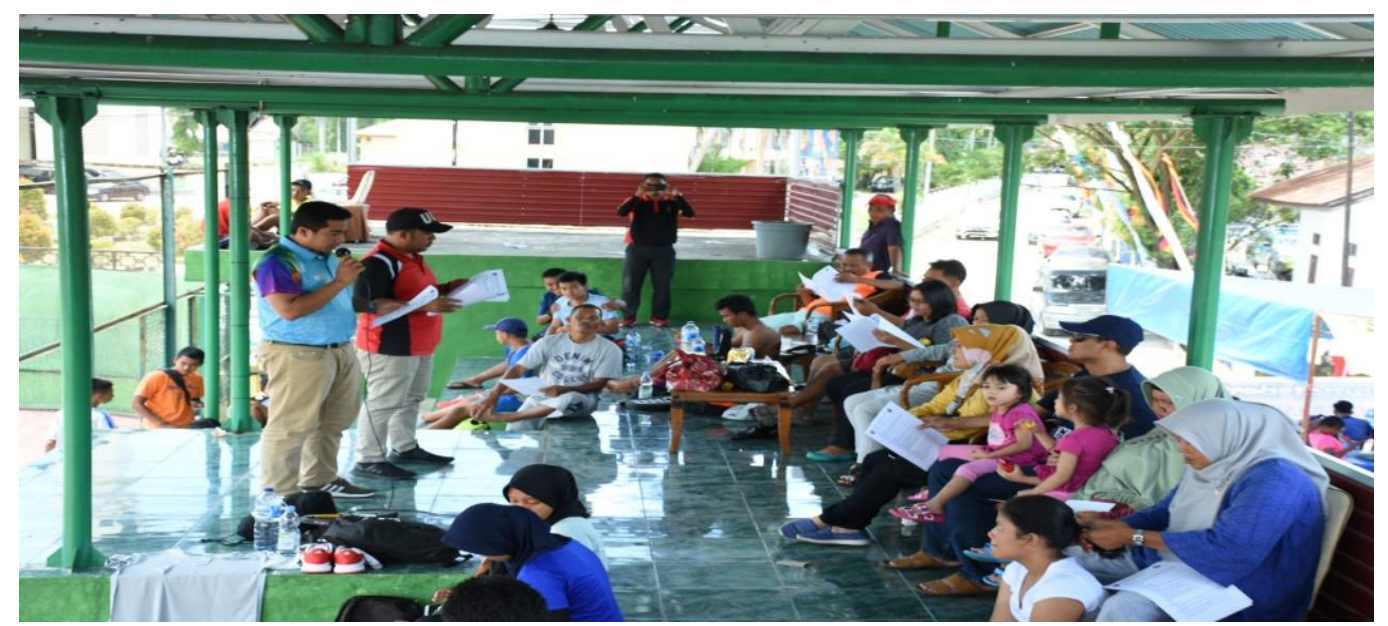

Gambar 1: Materi Kode Etik Bersama Pemateri Rices Jatra, M.Pd dan Rezki, M.Pd

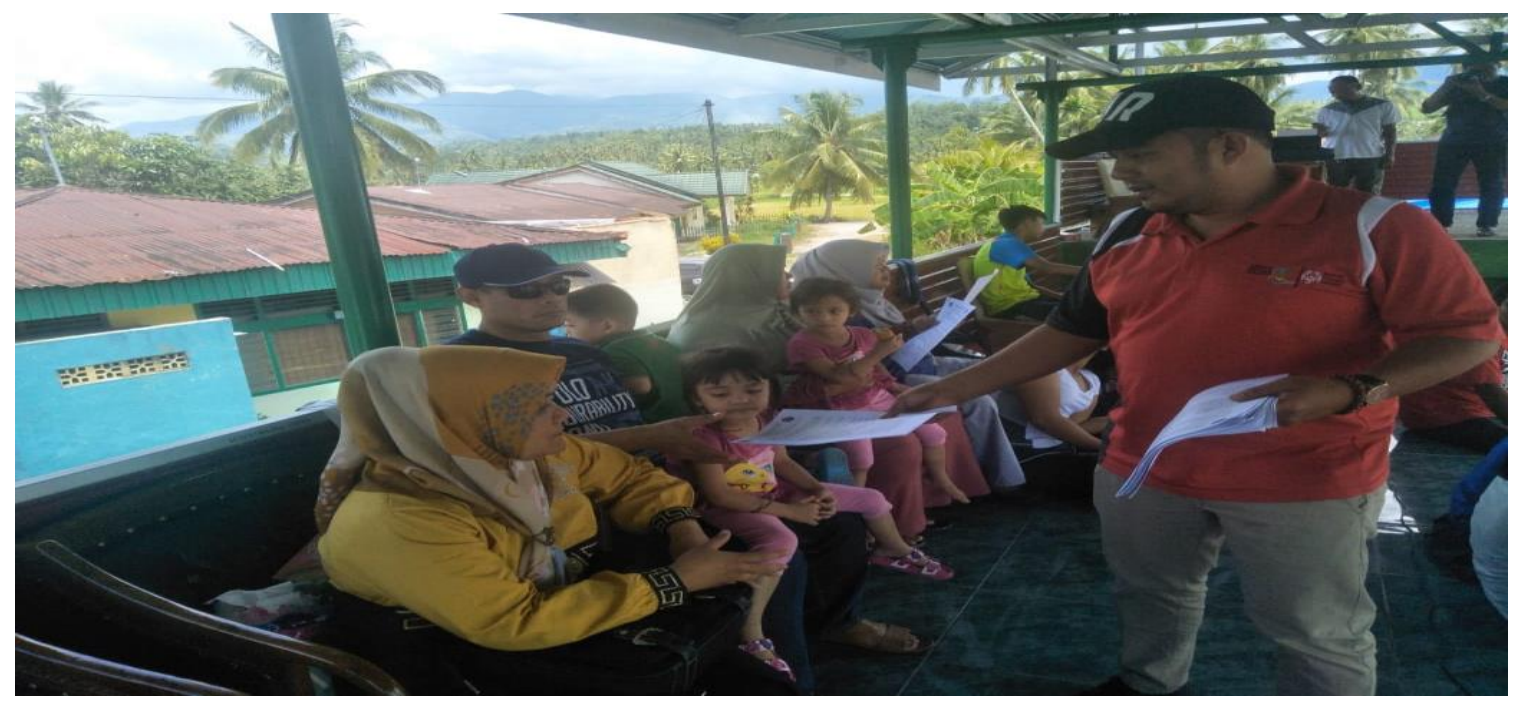

Gambar 2: Materi dibagikan oleh Rezki, M.Pd pada orang tua dan pelatih

Banyak hal yang ditanyakan oleh orang tua salah satunya mengenai aturan pertandingan, terkadang antara pertandingan yang satu dengan yang lain itu tidak sama. Sebagai contoh ada kejuaraan memakai sistem proset ada juga yang memakai sistem the best of tree ataupun memakai sistem the best of tree with no add scoring and Deciding Match Tie-break (10 points). Alasannya kenapa bisa seperti itu hal pertama yang menjadi penyebab antaranya dalam aturan untuk kelompok usia 10 dan 12 tahun itu memakai sistem pro set sedangkan untuk kU 14, 16 dan 18 memakai sistem The Best of Two Super Tiebreak Sets. Bila jumlah peserta,

Jumlah lapangan dan waktu yang tersedia tidak mencukupi, maka dapat menggunakan sistem Pro-Set, atau Short-Set, atau Deciding Match Tie-break (10 points). Khusus untuk Babak Kualifikasi Ganda menggunakan sistim Pro-Set. Ini tergantung kondisi saat pertandingan tersebut. Karna berbagai kejuaraan di sumatera pada umumnya ataupun di Indonesia banyak bermain di lapangan outdoor. 


\section{KESIMPULAB}

Tata tertip adalah peraturan-peraturan yang harus ditaati atau dilaksanakan, tata tertip Pertandingan adalah peraturan peraturan yang harus ditaati dan dilaksanakan dalam suatu kejuaraan atau pertandingan.Sebagai orang tua dan pelatih atlet tenis lapangan harus mengetahui mengenai tata tertip dalam pertandingan tenis lapangan dari sosialisasi ini dapat kesimpulan tata tertip adalah sesuatu aturan yang harus menjadi tanggung jawab bagi atlet dalam mengikuti pertandingan tenis lapangan. PP PELTI telah mengatur tata tertip pentandingan supaya bisa diterapkan dalam setiap penyelenggaraan pertandingan baik itu turnament daerah maupun turnament nasional. Sehingga akan membiasakan pemain bermain dengan fair play. Dari hasil sosialisasi pengabdian masyarakat ini, orang tua dan pelatih merasa senang karna tahu dengan aturan aturan tata tertip dalam pertandingan. Serta peserta juga mengetahuai bagaimana caranya membuat suatu pertandingan nasional dan langkah langkah menjadi seorang atlet nasional.

\section{Daftar Pustaka}

Arie Asnaldi;, \& Padang), (Jurusan Pendidikan Olahraga Prodi. Pendidikan Jasmani Kesehatan dan Rekreasi Fakultas Ilmu Keolahragaan; Universita Negeri. (2016). HUBUNGAN PENDEKATAN LATIHAN MASSED PRACTICE DAN DISTRIBUTED PRACTICE TERHADAP KETEPATAN PUKULAN LOB PEMAIN BULUTANGKIS. Jurnal Menssana, 1(2), 20-27.

Firdaus, kamal. (2012). Psikologi Olahraga Teori dan Aplikasi. Padang: UNP Press. harris. (2007). Panduan penilaian kelompok mata pelajaran jasmani olahraga dan kesehatan. Jakarta: BSNP (badan Standar Nasional Pendidikan.

International Tennis federation ITF. (2019). ITF - 2019 Rules of Tennis. London: ITF Limited t/a International Tennis Federation.

International Tennis Federation ITF. (2019). ITF DUTIES AND RESPONSIBILITIES FOR OFFICIALS A. In ITF Limited. London: ITF LTD.

ITF World Tennis tour Juniors. (2019). 2019 ITF WORLD TENNIS TOUR JUNIORS REGULATIONS. London SW15, UK: ITF LTD.

Maksum, A. (2006). Ciri Kepribadian Atlet Berprestasi Tinggi. Disertasi, (January 2006). https://doi.org/10.13140/RG.2.2.18305.76646

PP PELTI. (2018). PERATURAN TURNAMEN DIAKUI PELTI KELOMPOK UMUM TAHUN 2018. Jakarta: PP PELTI.

PP PELTI. (2019). PERATURAN TURNAMEN DIAKUI PELTI KELOMPOK YUNIOR TAHUN 2019. Jakarta: Pengurus Pusat PELTI.

Rahmawati, I. dina. (2017). MANAJEMEN SUMBER DAYA OLAHRAGA TENIS LAPANGAN. Jurnal Pinus, 3(1), 25-31. 